\title{
ONE OF THE FOREMOST EXPERIMENTS OF THE TWENTIETH CENTURY STANLEY MILLER AND THE ORIGIN OF PREBIOTIC CHEMISTRY
}

\author{
JEFFREY L. BADA
}

Stanley Miller is best known for his classic 1953 experiment on the synthesis of early Earth organic compounds, in the context of the origins of life. However, he did several other experiments that are lesser known and, in some cases, have never been published. The finding in 2007 that Miller had archived dried solutions from his 1950s experiments offered the opportunity of analyzing the products of his early experiments using modern day state-of-the-art techniques. These results, along with Miller's results, have provided an inventory of the large variety of compounds that include amino acids, amines, simple peptides, hydroxy acids, simple hydrocarbons and urea, which can be synthesized under simulated early Earth conditions.

Keywords: amino acids, spark discharge, reducing atmosphere.

In the fall of 1952, a sixty-year-old Professor and Nobel Laureate, Harold C. Urey, and a 22-year-old graduate student, Stanley L. Miller, sat in an office in the Chemistry Department at the University of Chicago discussing how they might simulate the conditions and reactions that produced organic compounds on the early Earth. Miller had heard a lecture by Urey in the fall of 1951 which stimulated his interest in a scientific question long considered to be intractable: how did life on Earth originate from inanimate matter. After waiting almost a year, Miller finally got the courage to approach Urey about the possibility of doing an experiment to test Urey's ideas about how organic compounds might have been made on the young Earth. After some hesitation, Urey agreed to let Miller try to carry out an experiment, provided he could produce results within six months that suggested that the experiment was worth continuing. The problem that was the focus of their attention at the 1952 meeting was how to conduct an experiment that might show how some of the essential organic compounds thought to have been important for the origin of life might have been produced (Bada \& Lazcano, 2012).

MODELING THE EARLY EARTH IN THE LABORATORY

Urey and Miller recognized that the overall chemical processes that take place on the surface of the Earth involved three general components: energy, the atmosphere, and the oceans. But how would you simulate the interaction of these components in a laboratory-based experiment? Several types of energy were thought to be available, including cosmic and ultraviolet radiation, radioactive decay, heat and electrical discharges. They realized one problem with the use of radiation and heat as energy sources was that they were too energetic and would likely tend to destroy any organic compounds as rapidly as they were synthesized.

Thus, they chose to focus on electrical discharges as a source of energy in their experiment.

Chemists had been experimenting with electric sparks in gas mixtures since the pioneering eighteenth 


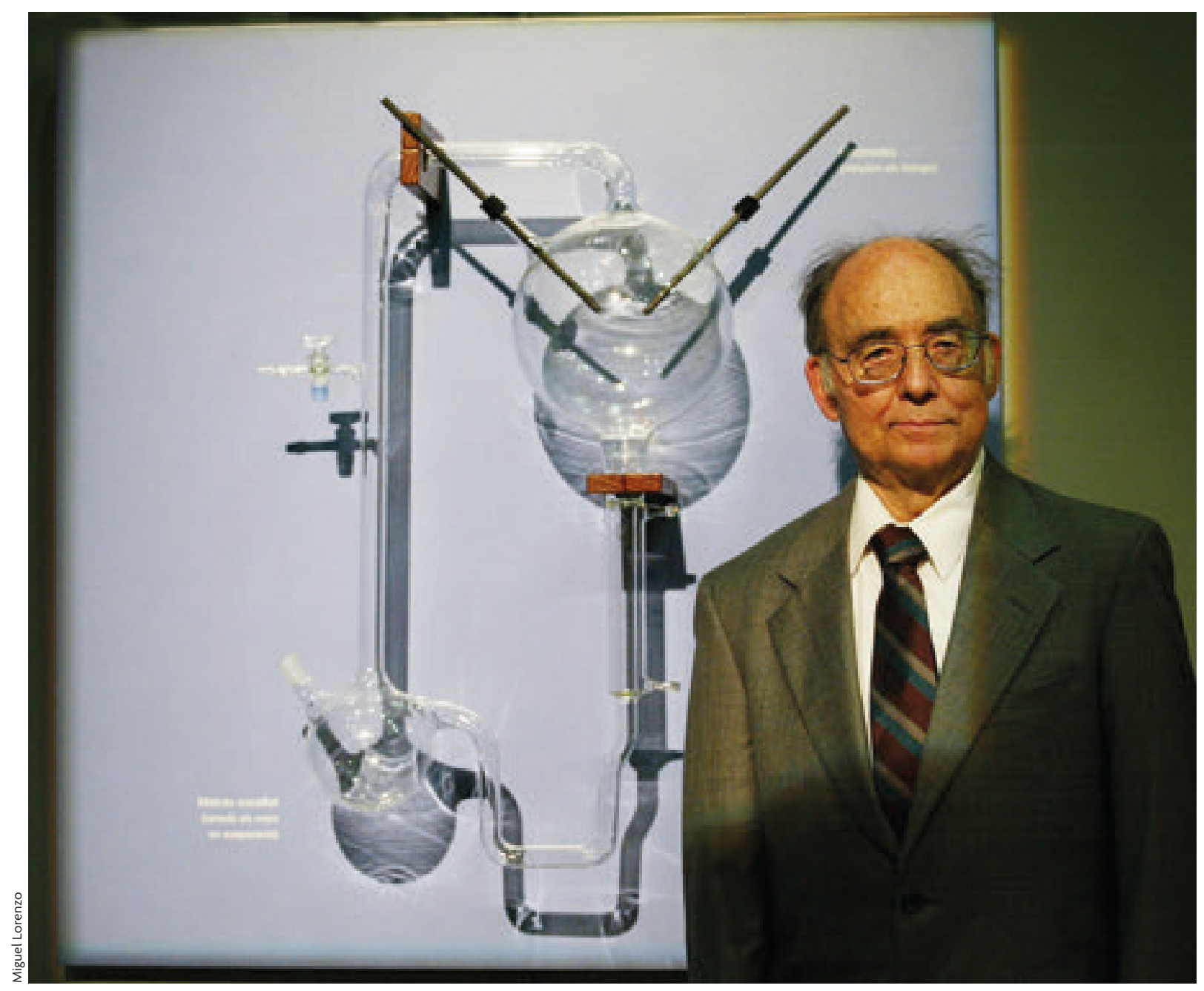

Stanley L. Miller at the Botanical Garden of the University of Valencia, during the first Pelegrí Casanova Conference of Biodiversity and Evolutionary Biology (2003), in front of an exact copy of the glass apparatus he designed in 1953.

century work by Lord Cavendish, who showed that the action of a spark discharge in air resulted in the production of nitrous acid (Cavendish, 1788). During the nineteenth century there was extensive research on the synthesis of simple organic compounds using a variety of conditions. In 1913 Walther Löb achieved the synthesis of the simple amino acid, glycine, by exposing wet formamide to a silent electrical discharge and to ultraviolet light (Löb, 1913). However, it appears that no one had thought about how these experiments might relate to prebiotic (before biology) synthesis and the origin of life.

Electric discharges were probably common on early Earth. The atmosphere must have been subject to extensive lightning along with corona discharges. Lightning would also have been associated with volcanic eruptions that were also likely to have been common on primitive Earth. In the laboratory, using a simple commercial Tesla coil, these electrical discharges can easily be made in order to simulate these processes.

On the modern Earth, one of the main features of the atmospheric-ocean interaction, besides heat exchange, is the evaporation of water and the condensation of this water from the atmosphere in the form of precipitation. On the Earth today the precipitation that falls on the continent is returned to the oceans by river discharges. On a global average, rivers discharge about $4.2 \times 10^{16}$ liters per year of water into the oceans (Fekete, Vörörsmarty, \& Grabs, 2002). Because the Earth's oceans contain $1.3 \times 10^{21}$ liters of water, this means river water discharge would provide all the ocean water in only $\sim 30,000$ years.

On the early Earth, there were probably a few major continents, with the only land areas exposed above the ocean surface being relatively small islands. 


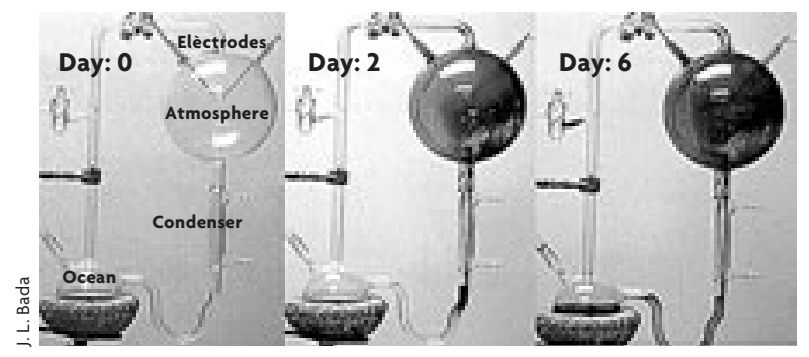

Figure 1. A time series of the Miller experiment showing the accumulation of brownish tar. Amino acids and other organic compounds accumulate in the "Ocean" flask. Frames taken from a video made in Miller's laboratory by several of his students and J. L. Bada circa 1997 and 1998.

Thus riverine-type water run-off would not have been a major component of the water cycle. Rather, precipitation falling directly on the surface ocean would have been the dominant way water evaporated from the ocean would be returned to the ocean.

In order to model these overall processes, Urey and Miller came up with a design for a glass apparatus that included a water flask connected to a larger flask connected to electrodes that provided energy through electrical discharge (see Figure 1). The water flask could be heated to replicate evaporation. There was also another connector between the 2 flasks that had a condenser that would act to condense water from the gas phase and return it to the water flask, simulating precipitation. The apparatus was first evacuated to remove any traces of air (oxygen could have produced an explosion) and

"ANALYSES OF THE VIALS FROM THE ORIGINAL EXPERIMENT REPORTED IN 'SCIENCE' IN 1953 REVEALED THAT THIRTEEN AMINO ACIDS AND FIVE AMINES HAD BEEN SYNTHESIZED COMPARED TO THE SEVEN AMINO ACIDS MILLER HAD REPORTED" stopped the experiment to determine what gases remained in the flask. Besides the initial gases hydrogen, methane, and ammonia, after sparking, carbon monoxide and nitrogen gases were also present. Based on the final amounts of methane and carbon monoxide and the initial amounts of methane, Miller estimated that $50-60 \%$ of the carbon originally present as methane had been converted into organic compounds, the vast majority of which consisted of complex polymeric materials (Miller, 1955).

Miller next analyzed the water solution and carried out some simple tests for some specific organic compounds. He detected amino acids such as glycine, alanine, $\beta$-alanine, and $\alpha$-amino butyric acid as well as formic acid, glycolic acid, lactic acid, acetic acid, and propionic acid. The experiment thus was the first to demonstrate how organic compounds associated with biochemistry could be synthesized under possible primordial-Earth conditions. The first paper was published in Science on 15 May $1953^{1}$ (Miller, 1953). This was widely covered in the media and as a result Miller became famous worldwide. $\mathrm{He}$ had just turned 23 years old. An interesting note about this renowned publication is that Miller was the sole author. Urey had told Miller when the paper was submitted for publication that he wanted Miller to be the only author. Urey felt that, if he were a co-author, everyone would give him all the credit.

Miller next set out to further characterize the various compounds produced in the experiment. He tried other variations of the original apparatus design as well as differing the relative amounts of the gases added to the apparatus. In total, Miller would report that over 20 different compounds were synthesized in the experiment. Miller also realized that the pathway by which the amino acids synthesized was likely the century-old (at the time of the experiments) Strecker reaction (Strecker, 1850) in which reactants such as hydrogen cyanide ( $\mathrm{HCN})$, aldehydes, and ketones, were produced in the spark discharge, and that when dissolved in the water in the presence of ammonia they reacted to yield amino acids (after a couple of

\footnotetext{
${ }^{1}$ Miller died on 20 May 2007, 54 years after the publication of this classic paper. The latest citation index shows this paper has been cited over 2,300 times.
}

The first results were spectacular! Soon after the spark discharge between the electrodes was started using the Tesla coil, the glass surfaces and the water in the apparatus turned brown (Figure 1). By the end of 6 days, everything was coated with a dark, gooey material resembling oil. Obviously some sort of chemistry took had taken place. Miller quickly 
intermediate steps). The same process synthesized the hydroxy acid Miller detected. The reaction sequences were as follows:

$$
\begin{aligned}
& \mathrm{HCN}+\text { Aldehydes } / \text { Ketones }+\mathrm{NH}_{3} \rightarrow \text { amino acids } \\
& \mathrm{HCN}+\text { Aldehydes/Ketones } \rightarrow \text { hydroxy acids }
\end{aligned}
$$

To test whether this reaction sequence explained some of the compounds Miller detected, he carried out further analyses on the water solution (Miller, 1957). He found that after running the experiment for 25 hours, $\mathrm{HCN}$ was present at a concentration of $\sim 40 \mu \mathrm{M}$ and aldehydes at $1 \mu \mathrm{M}$ and the total concentration of amino acids had reached $\sim 2 \mu \mathrm{M}$. These components were not detectable at the start of the experiment. In addition, the concentration of ammonia steadily decreased over the course of the experiment. This provided conclusive proof that the Strecker reaction was indeed the pathway by which amino acids were formed in the experiment. Other compounds Miller detected such as urea could be synthesized simply from ammonium and cyanate (formed in the spark discharge), a reaction first discovered by Friedrich Wöhler in 1828 (Wöhler, 1828).

\section{FINDING A HISTORIC TREASURE}

Starting in late 1999, Miller suffered a series of strokes that left him increasingly disabled. In 2005, I was asked to help clean out his laboratory and office in the University of California, San Diego (UCSD) Chemistry Department. A large amount of equipment, chemicals and files were moved into my laboratory and offices at the Scripps Institution of Oceanography (SIO). Then in March 2007 during a conversation with Antonio Lazcano, a mutual friend of Miller's, it was mentioned that Miller had once shown Antonio a box in his office that he said contained portions of his 1950s experiments. I immediately realized that this was likely somewhere among all of Miller's material that I had moved to my laboratories. It took only a short time to find two cardboard boxes with «Electric Discharge» written on one side that I recognized as Miller's handwriting. Inside the boxes were a series of clearly labeled small boxes containing small, tightly capped glass vials also labeled (Figure 2). The writing on the labels of the vials indicated the experiment number and the pages in his laboratory notebooks where the details

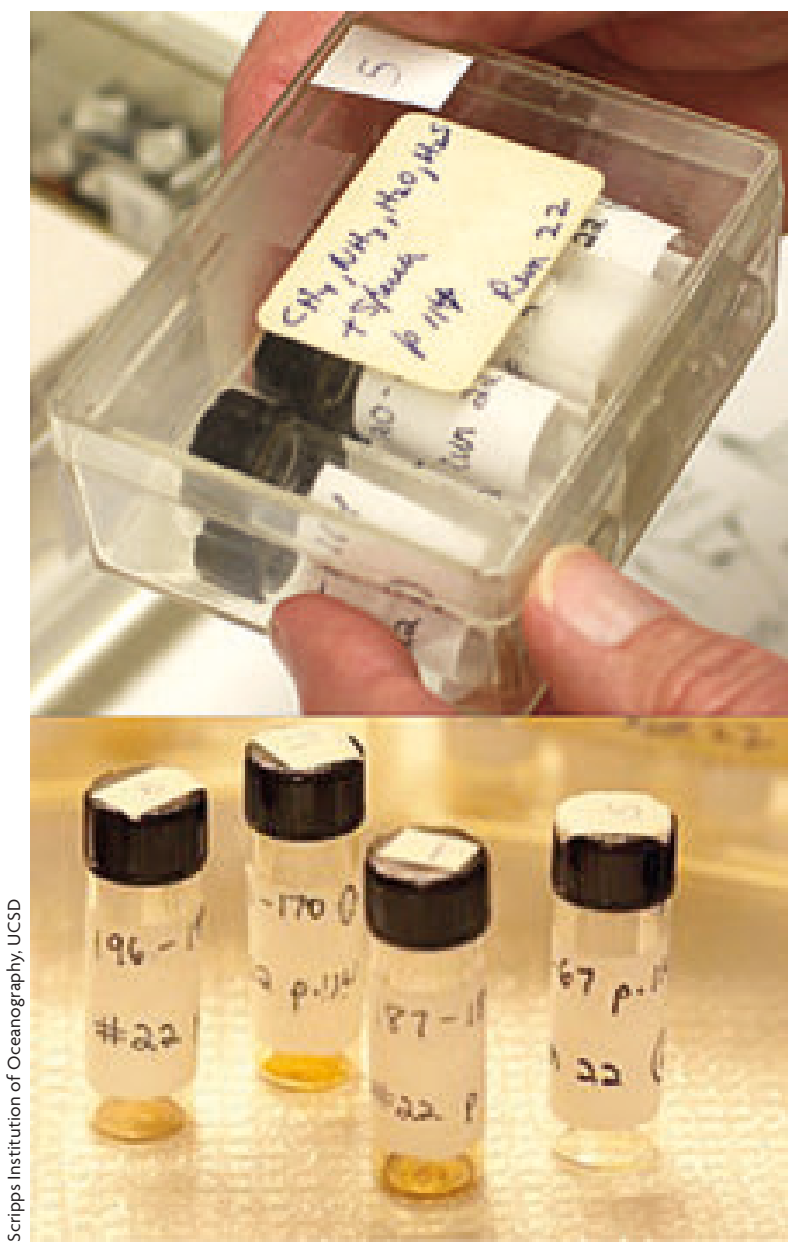

Figure 2. Examples of the boxes of samples containing vials with portions Miller saved from his early experiments.

of the experiments are described (these notebooks are in part of the Mandeville Special Collections at the Geisel Library, UCSD).

The vials in the various small boxes were from experiments Miller carried out as part of his thesis research in 1952-54 at the University of Chicago. Included were vials from his classic experiment described in the 1953 Science paper as well as others from experiments conducted with two different apparatus designs (Bada \& Lazcano, 2003). One differently configured apparatus had an aspirating nozzle attached to the water-containing flask, injecting a jet of steam and gas into the spark flask. A third apparatus design incorporated the aspirator device, but used a silent discharge instead of electrodes, an energy source that had been used by others in the 


\begin{tabular}{|c|c|}
\hline Amino acid & Moles relative to glycine $=1$ \\
\hline Glycine & 1.0 \\
\hline Glycolic acid & 0.89 \\
\hline Sarcosine (N-methylglycine) & 0.08 \\
\hline Alanine & 0.54 \\
\hline Lactic acid & 0.49 \\
\hline N-Methylalanine & 0.02 \\
\hline$\alpha$-Amino-n-butyric acid & 0.08 \\
\hline$\alpha$-Aminoisobutyric acid & $0.002^{*}$ \\
\hline$\alpha$-Hydroxybutyric acid & 0.08 \\
\hline$\beta$-Alanine & 0.24 \\
\hline Succinic acid & 0.06 \\
\hline Aspartic acid & 0.006 \\
\hline Glutamic acid & 0.01 \\
\hline Iminodiacetic acid & 0.09 \\
\hline Iminoacetic-propionic acid & 0.02 \\
\hline Formic acid & 3.70 \\
\hline Acetic acid & 0.24 \\
\hline Propionic acid & 0.21 \\
\hline Urea & $0.03^{*}$ \\
\hline \multirow{2}{*}{\multicolumn{2}{|c|}{$\begin{array}{l}\text { * Likely low because Miller did not realize the ninhydrin detection method he used had a lower } \\
\text { response for this amino acid compared with the other amino acids. } \\
\text { Table 1. Yields in moles (relative to glycine = 1) of the various } \\
\text { compounds Miller detected in his spark discharge experiments. The } \\
\text { amount of carbon added in the form of methane was } 710 \mathrm{mg} \text {. The } \\
\text { amount of glycine synthesized was } 4.8 \mathrm{mg} \text {. }\end{array}$}} \\
\hline & \\
\hline SOURCE: Based on Miller and Urey, 1959. & \\
\hline
\end{tabular}

early twentieth century to study how organic compounds might have been synthesized in plants (Bada \& Lazcano, 2002). Of these, the one with the aspirator device was intriguing because we surmised it could mimic a water rich volcanic eruption accompanied by lightning: thus it was dubbed the «volcanic» apparatus.

These archived samples provided a unique opportunity to investigate samples prepared by the pioneer in prebiotic synthesis using state of the art analytical methods unimaginable to Miller. We thus proceeded to analyze the vials associated with his 1952-54 experiments ${ }^{2}$ (for a more complete discussion of the results obtained from all the archived samples analyzed to date, see Bada, 2013). The residues in the various vials were resuspended in 1 $\mathrm{ml}$ aliquots of doubly-distilled water and reacted with

\footnotetext{
${ }^{2}$ Because Miller had found (1957) that the third apparatus produced lower yields and a less diverse mixture of amino acids we decided not to analyze the vials from this experiment.
}

OPA-NAC (o-phthaldialdehyde/N-acetyl-L-cysteine) to form highly fluorescent amino acid derivatives, which we characterized by a combination of high performance liquid chromatography with fluorescence detection, and liquid chromatography-fluorescence detection-time of flight mass spectrometry. Analyses of the vials from the original experiment reported in Science in 1953 revealed that thirteen amino acids and five amines had been synthesized compared to the seven amino acids Miller had reported (Table 1). In addition, analyses of the vials from the «volcanic» apparatus showed that twenty-one amino acids had been synthesized along with five amines (Johnson et al., 2008). The overall abundances of the various amino acids and amines appeared to be greater in comparison to what Miller reported. Hydroxylated compounds seemed to be preferentially synthesized in the «volcanic» experiment. This suggests that the steam injected into the spark apparently splits water into $\mathrm{H}^{*}$ and $\mathrm{OH}^{*}$ radicals. The $\mathrm{OH}^{*}$ radicals likely hydroxylated the aldehydes and ketones and these in turn reacted via the Strecker reaction to produce the hydroxylated amino acids detected in the extracts. Publication of these results has rekindled interest in Miller's pioneering work.

We next turned our attention to boxes of vials from experiments carried out in 1958. For reasons that are unknown, as far as we could ascertain, Miller had never analyzed these after the experiment was carried out. One set of vials was from an experiment in which hydrogen sulfide $\left(\mathrm{H}_{2} \mathrm{~S}\right)$ was part of the gas mixture.

We carried out detailed analyses of these samples using the technique described for the «volcanic» apparatus. In total, 23 amino acids and 4 amines, including 6 sulfur-containing amino acids and 1 sulfurcontaining amine, were detected (Parker et al., 2011). There was also evidence indicating that several other higher carbon amino acids were generated, but at much lower relative amounts. The $\mathrm{H}_{2} \mathrm{~S}$ experiment also generated amino acids such as threonine, leucine, and isoleucine, which were not detected in Miller's other spark discharge experiments. In addition, the 1958 $\mathrm{H}_{2} \mathrm{~S}$ experiment provided the first demonstration of the production of a variety of organosulfur compounds from a spark discharge experiment designed to mimic possible primitive Earth conditions. 
An interesting aspect of the $\mathrm{H}_{2} \mathrm{~S}$ experiment was that the overall relative amino acid abundances were remarkably similar to those found in certain carbonaceous meteorites (Parker et al., 2011). Various lines of evidence suggest that the meteorite amino acids were synthesized during an early aqueous alteration process on the asteroid that was the parent body of the meteorite (Bada, 2013; Burton, Stern, Elsila, Glavin, \& Dworkin, 2012; Peltzer, Bada, Schlesinger, \& Miller, 1984). It is likely that reactants such as HCN, aldehydes/ketones and ammonia had been synthesized elsewhere in which, besides gases such as methane and hydrogen, $\mathrm{H}_{2} \mathrm{~S}$ was a component. These reactants were then incorporated into the parent bodies where amino acids were eventually synthesized by water liberated in the interior that percolated to the surface.

Several additional boxes of samples still remained in the collection we had found. After carefully reviewing these for differences in gas mixture composition, apparatus design, etc., we decided to next direct our attention to another set of 1958 samples in which Miller had carried out an experiment that involved sparking a gas mixture of $\mathrm{CH}_{4}, \mathrm{NH}_{3}$, and $\mathrm{H}_{2} \mathrm{O}$, while intermittently adding the plausible prebiotic condensing agent cyanamide during the course of the experiment. Nearly fifty years ago, cyanamide was found to be synthesized from reduced gases by UV light and was proposed to be a possible prebiotic condensing agent (Schimpl, Lemmon, \& Calvin, 1965). How Miller got the idea of using cyanamide in a spark discharge experiment, nearly a decade before this was suggested by others as an agent for polymerizing amino acids, is a mystery.

Our analyses found that more than 12 amino acids, 10 glycine-containing dipeptides, and 3 glycinecontaining diketopiperazines (DKPs), cyclic dipeptides, were synthesized in the experiment (Parker et al., 2014). However, there was a problem: previous studies of the polymerization of amino acids by cyanamide indicated that the reaction took place at acidic $\mathrm{pH}$ values whereas the $\mathrm{pH}$ of the spark discharge solute was 8.5-9 (this was because of the ammonia in the spark discharge experiment). We confirmed this using an aqueous amino acid solution also containing cyanamide heated at $\mathrm{pH}$ values ranging from 2-3 to 10 . Our results confirmed that the polymerization was optimal at acidic $\mathrm{pH}$. We suspected that the intermediates in the Strecker reaction leading to amino acids, amino acid nitriles, and amides, might be reacting with cyanamide rather than the amino acids themselves. We tested this using aqueous solutions at various $\mathrm{pH}$ values that contained either the amino acid nitrile or amino acid amide along with cyanamide. The results showed

\begin{tabular}{lll}
\hline Amino Acids & Amines & Peptides \\
\hline Glycine & Methylamine & Glycyl-alanine \\
\hline Alanine & Ethylamine & Glycyl-threonine \\
\hline$\beta$-Alanine & Ethanolamine & Glycyl-proline \\
\hline Serine & Isopropylamine & Prolyl-glycine \\
\hline Isoserine & N-Propylamine & Glycyl-valine \\
\hline$\alpha$-Aminoisobutyric acid & Cysteamine & Valyl-glycine \\
\hline$\beta$-Aminoisobutyric acid & & Glycyl-glutamic acid \\
\hline$\alpha$-Aminobutyric acid & Glutamyl-glycine \\
\hline$\beta$-Aminobutyric acid & Leucyl-glycine \\
\hline$\gamma$-Aminobutyric acid & cyclo(Glycyl-glycine) \\
\hline Homoserine & cyclo(Glycyl-Proline) \\
\hline$\alpha$-Methylserine & cyclo(Leucyl-Glycine) \\
\hline Threonine & \\
\hline Aspartic acid & \\
\hline$\beta$-Hydroxyaspartic acid & & \\
\hline Valine & \\
\hline Isovaline & \\
\hline Norvaline & \\
\hline Ornithine & \\
\hline Glutamic acid & \\
\hline$\alpha$-Methylglutamic acid & \\
\hline Leucine & \\
\hline Isoleucine & \\
\hline$\alpha$-Aminoadipic acid & \\
\hline Phenylalanine & \\
\hline Homocysteic acid & \\
\hline S-Methylcysteine & \\
\hline Methionine & \\
\hline Methionine sulfoxide & \\
\hline Methionine sulfone & \\
\hline
\end{tabular}

Table 2. The various amino acids, amines and peptides detected in the 1950s Miller spark discharge experiments.

SOURCE: Johnson et al., 2008; Parker et al., 2011; Parker et al., 2014.
«MILLER'S PIONEERING STUDIES HELPED
DEFINE THE PROCESSES THAT PROVIDED
THE PREBIOTIC CHEMICAL INVENTORY
NEEDED FOR CHEMICAL EVOLUTION AND EVENTUALLY THE ORIGIN OF LIFE» 
that polymerization at $\mathrm{pH} 8.5-10 \mathrm{did}$, indeed, yield dipeptides with the main reactive species being the amino acid amide. These experiments confirmed that intermediates in the Strecker synthesis of amino acids play a key role in facilitating polymerization in the presence of cyanamide.

Miller's cyanamide experiment highlights the potential importance of condensing agents in providing a mechanism to explain how simple organic compounds like amino acids may have polymerized to form more complex biomolecules, such as dipeptides. The synthesis of dipeptides and diketopiperazines by the cyanamide polymerization reaction may have additional implications, as some dipeptides and DKPs have been found to have catalytic properties that may have been important on the primordial Earth (Weber \& Pizzarello, 2006).

\section{CONCLUSIONS}

Miller's pioneering studies helped define the processes that provided the prebiotic chemical inventory needed for chemical evolution and eventually the origin of life. The re-analyses using modern state-of-the-art analytical methods of archived portions that Miller had saved from his ground-breaking experiments in 1950s have found that he synthesized 31 amino acids, 6 amines, and 12 dipeptides/cyclodipeptides (Table 2). Miller's studies of the use of a prebiotic condensation agent suggests there are plausible pathways for generating more complex molecules from simple ones such as amino acids. Although much still needs to be done, the realization that the continuous prebiotic chemical evolution can likely generate molecules that have increasing complexity is important. As this increase in chemical complexity continued, polymers with some sort of primitive catalytic functions, were eventually produced. This, in turn, evolved into a complex polymeric molecule that could catalyze its own imperfect replication. It marked the point of both the origin of life and evolution.

In the book Elegant solutions: Ten beautiful experiments in chemistry (Ball, 2005), Miller's seminal work is selected along with such notable achievements by Henry Cavendish, Louis Pasteur, Ernest Rutherford, and Marie and Pierre Curie. This is certainly a fitting recognition of Miller's classic research.

\section{REFERENCES}

Bada, J. L. (2013). New insights into prebiotic chemistry from Stanley Miller's spark discharge experiments. Chemical Society Reviews, 42, 2186-2196. doi: 10.1039/c3cs35433d
Bada, J. L., \& Lazcano, A. (2002). Miller revealed new ways to study the origins of life. Nature, 416, 475. doi: 10.1038/416475a

Bada, J. L., \& Lazcano, A. (2003). Prebiotic soup-Revisiting the Miller experiment. Science, 300, 745-746. doi: 10.1126/science.1085145

Bada, J. L., \& Lazcano, A. (2012). Stanley L. Miller (1930-2007): A biogrpahical memoir. Retrieved from the National Academy of Sciences (USA) website: http://www.nasonline.org/memoirs

Ball, P. (2005). Elegant solutions. London: Royal Society of Chemistry. doi: 10.1039/9781847552600

Burton, A. S., Stern, J. S., Elsila, J. F., Glavin, D. P., \& Dworkin, J. P. (2012). Understanding prebiotic chemistry through the analysis of extraterrestrial amino acids and nucleobases in meteorites. Chemical Society Reviews, 41, 5459-5472. doi: 10.1039/C2CS35109A

Cavendish, H. (1788). On the conversion of a mixture of dephlogisticated and phlogisticated air into nitrous acid, by the electric spark.

Philosophical Transactions of the Royal Society of London, 78, 261-276.

Fekete, B. M., Vörösmarty, C. J., \& Grabs, W. (2002). High-resolution fields of global runoff combining observed river discharge and simulated water balances. Global Biogeochemical Cycles, 16(3), 1-10. doi: 10.1029/1999GB001254

Johnson, A. P., Cleaves, H. J., Dworkin, J. P., Glavin, D. P., Lazcano, A., \& Bada, J. L. (2008). The Miller volcanic spark discharge experiment. Science, 322, 404. doi: 10.1126/science.1161527

Löb, W. (1913). Über das Verhalten des Formamids unter der Wirkung der stillen Entladung Ein Beitrag zur Frage der Stickstoff-Assimilation. Berichte der deutschen chemischen Gesellschaft, 46(1), 684-697.

Miller, S. L. (1953). A production of amino acids under possible primitive earth conditions. Science, 117, 528-529. doi: 10.1126/science.117.3046.528

Miller, S. L. (1955). Production of some organic compounds under possible primitive earth conditions. Journal of the American Chemical Society, 77, 2351-2361. doi: 10.1021/ja01614a001

Miller, S. L. (1957). The mechanism of synthesis of amino acids by electric discharges. Biochimica et Biophysica Acta, 23, 480-489. doi: 10.1016/0006-3002(57)90366-9

Miller, S. L., \& Urey, H. C. (1959). Organic compound synthesis on the primitive Earth. Science, 130, 251-251. doi: 10.1126/science.130.3370.245

Parker, E. T., Cleaves, H. J., Dworkin, J. P., Glavin, D. P., Callahan, M., Aubrey, A., Lazcano, A., \& Bada, J. L. (2011). Primordial synthesis of amines and amino acids in a 1958 Miller $\mathrm{H}_{2} \mathrm{~S}$-rich spark discharge experiment. Proceedings of the National Academy of Sciences, 108, 5526-5531. doi: 10.1073/pnas.1019191108

Parker, E. T., Zhou, M., Burton, A. S., Glavin, D. P., Dworkin, J. P., Krishnamurthy, R., Fernández, F. M., \& Bada, J. L. (2014). A plausible simultaneous synthesis of amino acids and simple peptides on the primordial Earth. Angewandte Chemie, 126, 8270-8274. doi: 10.1002/ ange. 201403683

Peltzer, E. T., Bada, J. L., Schlesinger, G., \& Miller, S. L. (1984). The chemical conditions on the parent body of the Murchison meteorite: Some conclusions based on amino, hydroxy and dicarboxylic acids. Advances in Space Research, 4, 69-74. doi: 10.1016/0273-1177(84)90546-5

Schimpl, A., Lemmon, R. M., \& Calvin, M. (1965). Cyanamide formation under primitive Earth conditions. Science, 147, 149-150. doi: 10.1126/ science.147.3654.149

Strecker, A. (1850). Ueber die künstliche Bildung der Müchsaure und einen neuen, dem Glycocoll homologen Körper. Liebigs Annalen der Chemie, $75,27-45$.

Weber, A. L., \& Pizzarello, S. (2006). The peptide-catalyzed stereospecific synthesis of tetroses: A possible model for prebiotic molecular evolution. Proceedings of the National Academy of Sciences, 103, 12713-12717. doi: 10.1073/pnas.0602320103

Wöhler, F. (1828). Sur la formation artificielle de l'urée. Annual Review of Physical Chemistry, 37, 330-333.

Jeffrey L. Bada. Distinguished Research Professor, and Distinguished Professor Emeritus, of Marine Chemistry at the Scripps Institution of Oceanography, University of California, San Diego (USA). He obtained his PhD in Chemistry at UCSD in 1968 where Stanley Miller supervised his thesis research. His research deals with the environments on the early Earth that provided the optimal conditions for the synthesis of organic compounds required for the origin of life. 